\title{
Perceptions of surgical specialists in general surgery, orthopaedic surgery, urology and gynaecology on teaching endoscopic surgery in The Netherlands
}

\author{
M. P. Schijven - B. M. A. Schout • V. E. M. G. Dolmans · A. J. M. Hendrikx • \\ I. A. M. J. Broeders · I. H. M. Borel Rinkes
}

Received: 3 March 2007 / Accepted: 13 June 2007 / Published online: 31 August 2007

(C) Springer Science+Business Media, LLC 2007

\begin{abstract}
Background Specific training in endoscopic skills and procedures has become a necessity for profession with embedded endoscopic techniques in their surgical palette. Previous research indicates endoscopic skills training to be inadequate, both from subjective (resident interviews) and objective (skills measurement) viewpoint. Surprisingly, possible shortcomings in endoscopic resident education have never been measured from the perspective of those individuals responsible for resident training, e.g. the program directors. Therefore, a nation-wide survey was conducted to inventory current endoscopic training initiatives and its possible shortcomings among all program directors of the surgical specialties in the Netherlands.

Methods Program directors for general surgery, orthopaedic surgery, gynaecology and urology were surveyed using a validated 25-item questionnaire.

Results A total of 113 program directors responded (79\%). The respective response percentages were $73.6 \%$ for general surgeons, $75 \%$ for orthopaedic surgeon, $90.9 \%$ for urologists and $68.2 \%$ for gynaecologists. According to the findings, $35 \%$ of general surgeons were concerned about whether residents are properly skilled endoscopically upon completion of training. Among the respondents, $34.6 \%$ were unaware of endoscopic training initiatives. The
\end{abstract}

M. P. Schijven ( $\square)$ · I. A. M. J. Broeders .

I. H. M. Borel Rinkes

Department of Surgery, University Medical Center Utrecht,

Heidelberglaan 100, PO box 85500, 3508 GA, Utrecht,

the Netherlands

e-mail: m.p.schijven@umcutrecht.nl

B. M. A. Schout - V. E. M. G. Dolmans - A. J. M. Hendrikx Department of Urology, Catharina Hospital Eindhoven, PO box 1350, 5602 ZA, Eindhoven, the Netherlands general and orthopaedic surgeons who were aware of these initiatives estimated the number of training hours to be satisfactory, whereas the urologists and gynaecologists estimated training time to be unsatisfactory. Type and duration of endoscopic skill training appears to be heterogeneous, both within and between the specialties. Program directors all perceive virtual reality simulation to be a highly effective training method, and a multimodality training approach to be key. Respondents agree that endoscopic skills education should ideally be coordinated according to national consensus and guidelines.

Conclusions A delicate balance exists between training hours and clinical working hours during residency. Primarily, a re-allocation of available training hours, aimed at core-endoscopic basic and advanced procedures, tailored to the needs of the resident and his or her phase of training is in place. The professions need to define which basic and advanced endoscopic procedures are to be trained, by whom, and by what outcome standards. According to the majority of program directors, virtual reality (VR) training needs to be integrated in procedural endoscopic training courses.

Key words Endoscopic skills training ·

Virtual reality simulation - Minimal invasive surgery · Education · Resident training

Numerous surgical procedures across a broad spectrum of clinical specialties have become adapted to endoscopic surgery. Progress has been made regarding consensus guidelines in endoscopic surgical techniques [1-13]. Skills needed for performing this type of surgery safely cannot simply be transferred from skills derived from performing open surgery. It is neither appropriate nor effective, since skills needed to perform endoscopic procedures are 
markedly different in nature [14]. Improvement of endoscopic surgical performance depends, in fact, largely on practising endoscopic surgery [15]. Specific training in endoscopic skill and procedure has thus become a necessity for professions having embedded endoscopic techniques in their surgical palette. Previously, endoscopic skills training has shown to be inadequate, resulting both from subjective (resident interviews) and objective (skills measurement) research data [16-20]. Tight operating room schedules, shortened surgical trainings curricula and medico-legal issues have left surgical educators wondering whether the operating theatre should be the primary teaching environment for acquisition of surgical skills [21, 22]. Next to surgical educators, the surgical endoscopic community itself has become aware of the necessity of shortening learning curves in the operating room. Much controversy, however, exists in terms of the amount and format of preoperating room training necessary for safe performance of various endoscopic procedures [23, 24]. Recently, multiple randomised studies have been able to show a beneficial impact on trainee's endoscopic performance after training with innovative training devices, such as virtual reality simulators [25-29].

Surprisingly, possible shortcomings in endoscopic resident education have never been monitored, nor measured, from the perspective of those individuals primarily responsible for resident training. Such a person, often being a practising surgical specialist who is referred to as the residents' program director; teaches, monitors and is formally held responsible for the progress of the particular surgical resident. For successful design and implementation of curriculum guidelines, it is of paramount importance to know perspectives related to the issue from within this particular group of surgeons.

This study provides an overview of the current opinion and possible shortcomings of endoscopic training and curriculum design in the Netherlands, as perceived by program directors. Program directors for all main surgical specialties performing endoscopic surgery in the Netherlands, e.g. general surgeons, orthopaedic surgeons, urologic surgeons and gynaecologists, were addressed.

\section{Methods and Materials}

\section{Questionnaire}

A specific, piloted questionnaire was developed for the purpose of study, e.g. a nationwide, interdisciplinary investigation considering program directors' perspectives in current training issues concerning endoscopic surgical skills. The questionnaire was sent to all Dutch hospitals known to formally train residents in the surgical specialties.
It was addressed to the program director. Upon initial nonreply, two reminders were sent using regular mail and email. For those who did not respond to these reminders, an alternative (online fill-in questionnaire, web format) opportunity was offered to gain maximum response numbers. Considering its lengthy format, a copy of the questionnaire can be obtained from the primary author upon readers' interest.

Scope of questionnaire

The questionnaire consisted of 25 questions/statements. Demographic variables were investigated, as well as experience with endoscopic surgery and endoscopic surgical training. Nineteen questions/statements specifically relate to endoscopic training of residents, its organization, perceived shortcomings and recommendations for improvement. Focus group testing for appropriate coverage of questions by members of the target group population was performed initially.

\section{Subjects}

The questionnaire was sent to all Dutch surgical specialists, responsible for resident education, as known by their respective organizations. Fifty-three general surgeons, 44 gynaecologic surgeons, 24 orthopaedic surgeons and 22 urologic surgeons were addressed.

\section{Statistical analysis}

According to the level of information of the data (nominal to interval), for comparison of measures of central tendency, appropriate testing was chosen. Data were graphically displayed using frequency tables and box plots, displaying medians, $25^{\text {th }}$ and $75^{\text {th }}$ percentiles as well as outliers and extremes. Probability levels for significance testing were set at the alpha level of 0.05 . Analyses were performed using the Statistical Package for the Social Sciences (SPSS) version 12.0.1 (SPSS, Chicago, IL, USA).

\section{Results}

In total, 113 program directors and endoscopic teachers responded (overall response percentage: 79\%). The response percentages per respondent group: general surgeons $73.6 \%$, orthopaedic surgeons $75 \%$, urologists $90.9 \%$ and gynaecologists $68.2 \%$. 


\section{Demographics of respondents}

Of all respondents, 105 were male. Seven respondents were female, all of them gynaecologists. One respondent replied, but without indicating his or her sex. Respondents' age ranged between 36 and 64 years, and did not differ significantly among the surgical specialties (Chi-Square Kruskal-Wallis test: 5,$121 ; P$-value $=0.163)$. Figure 1 shows the dispersion of respondents among the specialties.

Of all respondents, $9.9 \%$ replied not to be the program director, e.g. not the specialist primarily responsible for matters concerning education and training of residents. It is assumed that the questionnaire was handed over to these respondents by the program director initially addressed. This can be the case if the respondent is, in fact, a person to whom endoscopic resident training issues are formally delegated to by the program director. Therefore, these responses were considered to be of value, and were not omitted from the database. The mean number of years the specialist was appointed the position of primary responsible surgeon in matters regarding resident training and education was 6.4 years, ranging from 1-21 years; with a standard deviation of 5.18. This parameter did not differ significantly among specialties (Chi-Square Kruskal-Wallis test: $4.994 ; P$-value $=0.172$ ).

Over $90 \%(91.8 \%)$ of respondents perform endoscopic surgery themselves. The respective surgical speciality does not seem to be related to performance of endoscopic surgery (Chi-Square Kruskal-Wallis test: 1.565 ; $P$-value $=$ 0.667). The mean number of endoscopic operations performed is about 100 operations per year (99.96), with a standard deviation of almost the same magnitude (94.57). Figure 2 shows the dispersion among specialties. Here, significant differences between specialties exist; (ChiSquare Kruskal-Wallis test: $12.245 ; P$-value $=0.007)$, gynaecologists state a mean number of 68.7 operations

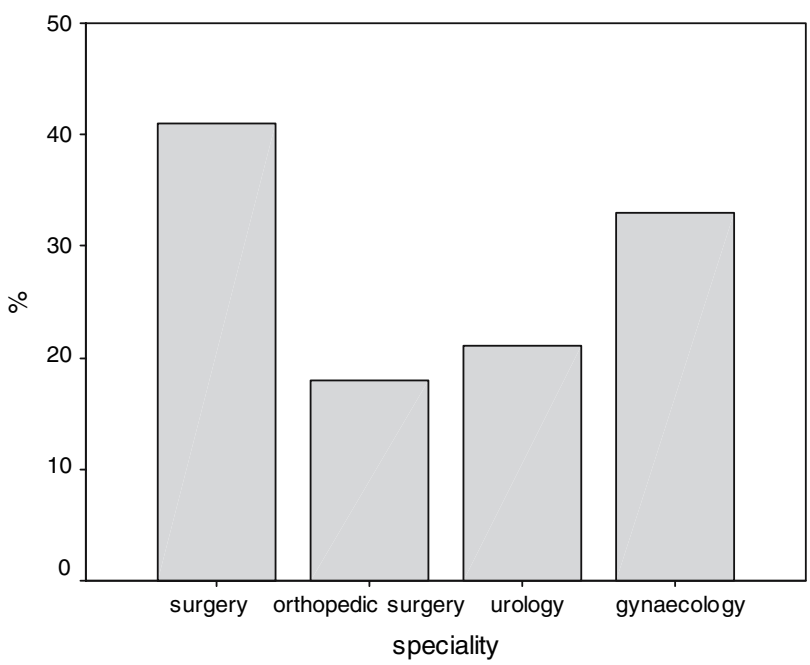

Fig. 1 Specialty (standard deviation 47.49) whereas orthopaedics state a mean number of 163 operations per year (standard deviation of 104.4).

As for teaching endoscopic surgical skill, about half of respondents (55\%), do so in a structured format (Fig. 3). No significant differences exist between specialty groups (Chi-Square Kruskal-Wallis test: $0.682 ; P$-value $=0.877$ ). Respondents who do teach endoscopic skill are significantly younger (mean age 49.7; standard deviation 5.78) than those who do not teach (mean age 53.34; standard deviation 4.89) endoscopic surgical skill (Student's $t$-test Sig 2-tailed 0.001).

Endoscopic resident training

Except for orthopaedic surgeons, respondents are not overtly concerned whether residents work enough clinical

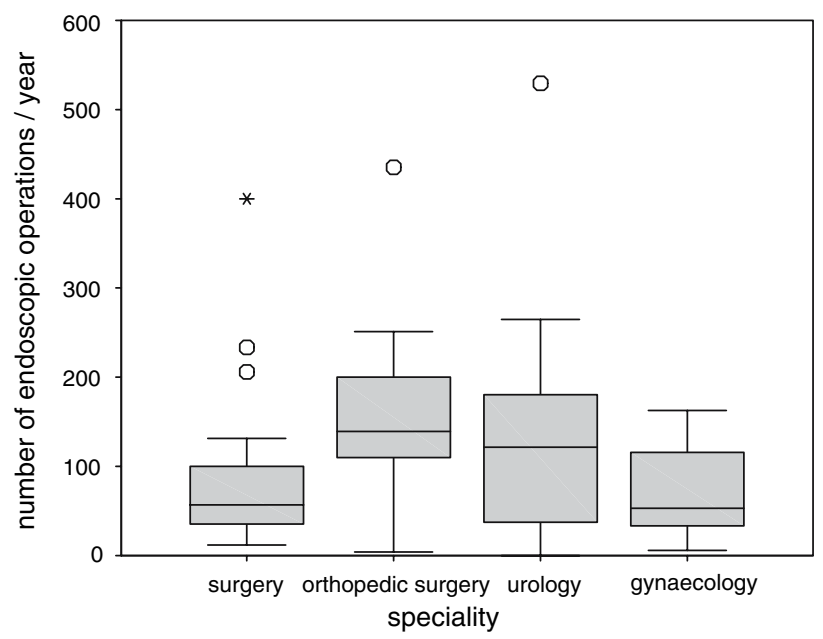

Fig. 2 Total number of endoscopic operations per year as performed by respondent

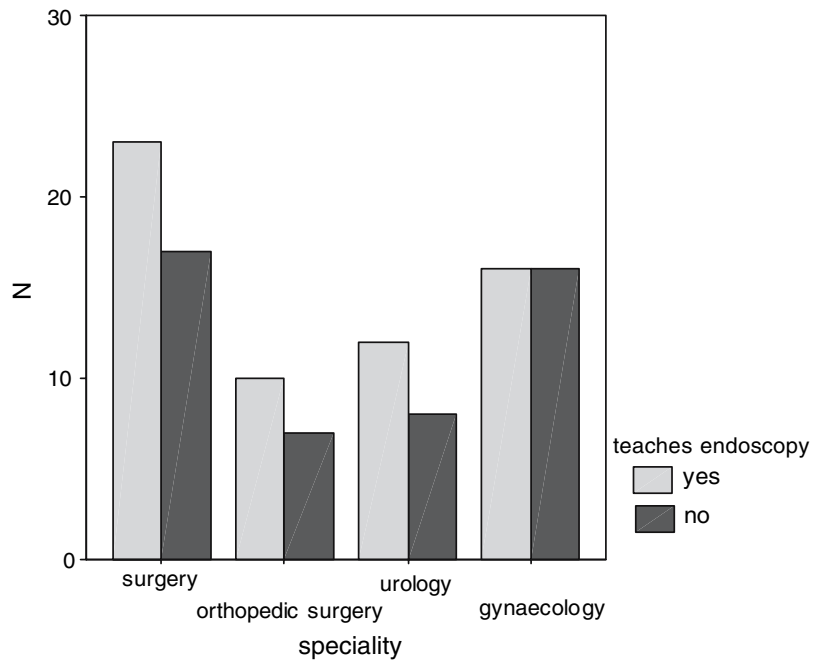

Fig. 3 Respondent teaches endoscopic skill in skills course 
hours to be adequately skilled for the profession upon completion of formal training, as graphically represented in figure 4 . They tend to agree on this aspect, as no significant differences between specialties exist (Chi-Square KruskalWallis test: $1.333 ; P$-value $=0.721$.

General surgeons do show some concern regarding residents to be proper endoscopically skilled, according to individual standards, upon completion of training (Statement 2). Orthopaedics, urologists and gynaecologists do not (Fig. 4). Again, there are no significant differences in opinion (Chi-Square Kruskal-Wallis test: 2.330; $P$-value $=$ $0.507)$.

Overall, in $55 \%$ of respondents' working clinic, endoscopic skills education is offered to the residents. In the Netherlands, structured resident education is often offered within geographic regions in collaboration with affiliate clinics. Therefore, regional initiatives concerning the issue were inventoried. A percentage of $65.4 \%$ of respondents indicate there were either local or regional training initiatives. Marked differences exist between the specialties concerned (Fig. 5, Chi-Square Kruskal-Wallis test: 18.472; $P$-value $=0.000$ ).

The majority of tutors aware of endoscopic training initiatives, indicate the number of obligatory hours offered for endoscopic training to be satisfactory (general surgeons, orthopaedics), to dissatisfactory (urologists, gynaecologists). Groups are either too small, or differences

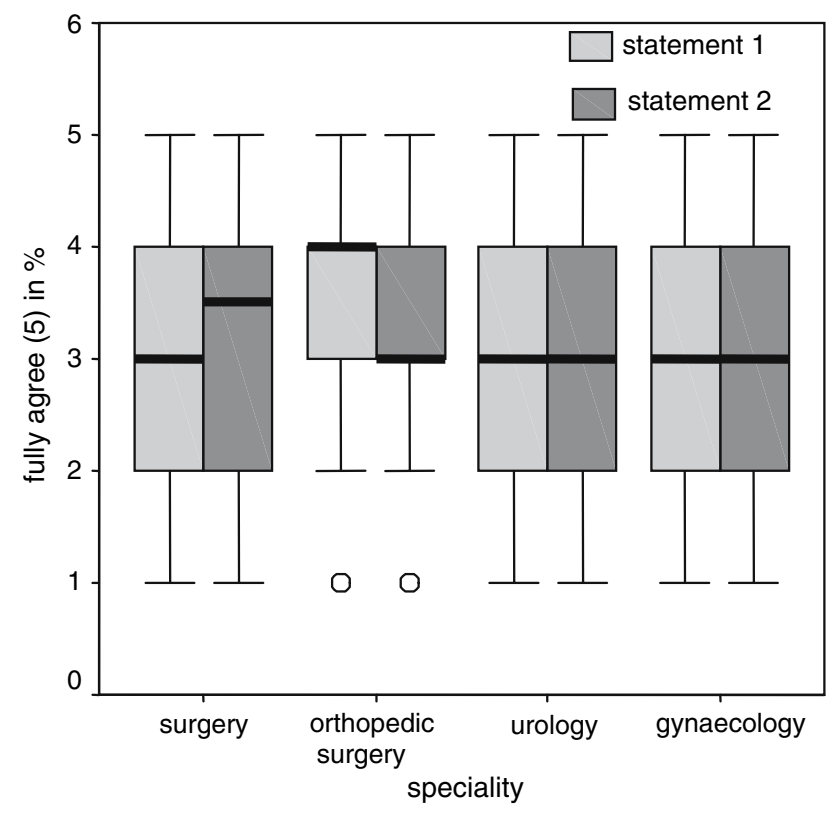

Fig. 4 Response on statements:

1. I am worried whether the current resident-in-training works enough clinical hours to be skilled upon completion of formal training.

2. I am worried whether the current resident in-training works enough clinical hours, in my opinion, to have adequate endoscopic skills upon completion of formal training

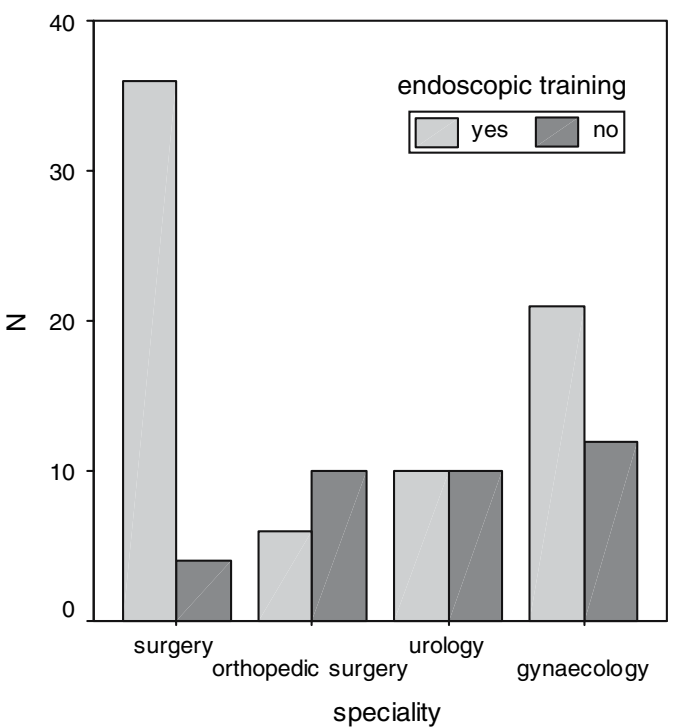

Fig. 5 Endoscopy taught in region

not large enough, to show significance (Fig. 6, Chi-Square Kruskal-Wallis test: $6.974 ; P$-value $=0.073$ ). No teacher offering obligatory training regimen(s) to residents feels the amount of training offered to be (much) too much.

The type and duration of endoscopic skill training appears to be heterogeneous, both within and between the specialities (Fig. 7). Responses were therefore grouped into categories. The outcome "combination" was used for those training formats using a variety of training modules, not embedded in a structured skills course. For surgery and gynaecology, endoscopic training is usually embedded in structured skills courses. Such courses are markedly different in outline and duration, aiming at various surgical endoscopic skills, offering a combination of different training modalities (video discussion, VR, box trainer, skillslab, in vivo lab sessions). These formats of training focus primarily on teaching basic psychomotor endoscopic skill to the residents. In surgery, no obligatory national training concepts exist for endoscopic surgery.

Only three surgeons mention laparoscopic procedures to be trained in their region. Procedures mentioned are the laparoscopic cholecystectomy (mentioned three times), the laparoscopic appendectomy and the laparoscopic groin hernia correction (both mentioned once). One orthopaedic surgeon indicates his residents to receive procedural training, e.g. to train specifically on ankle arthroscopy. For urologic procedures, three urologists indicate the transurethral radical prostatectomy to be trained (once mentioned), the endoscopic pelvic lymph node dissection (once mentioned), and transurethral procedures including uretheroscopy (3 times mentioned).

Most gynaecologists mention the hysteroscopy course as well as the COBRA (Chirurgische Opleiding en Bijscholing Randstad Academies; a surgical training initiative) 


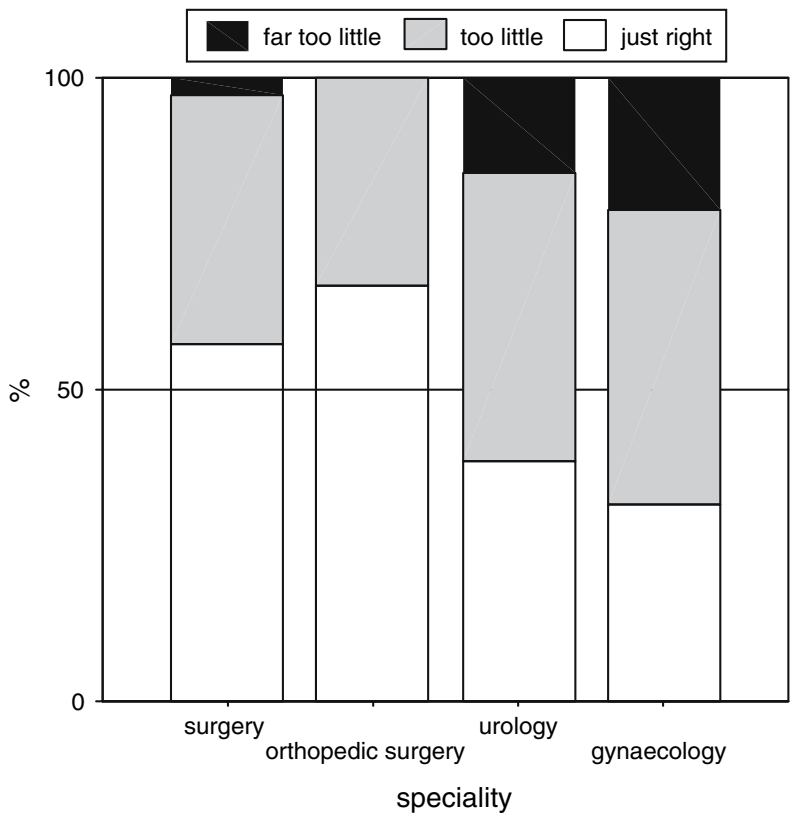

Fig. 6 Number of hours of obligatory training

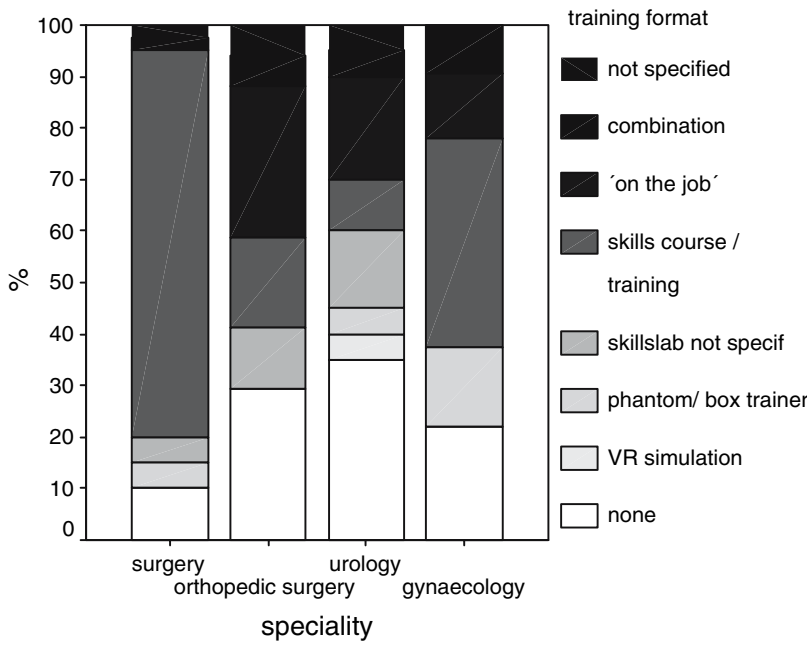

Fig. 7 Type of endoscopic skill training

course to be part of their nation-wide, obligatory resident training programme.

In contrast to the courses for surgical resident, The COBRA course, training basic surgical techniques and laparoscopic techniques, is aiming at third year residents. It might be compared to the surgical "Basic Surgical Skills Courses BSSC", incorporating half a day of laparoscopic basic skill training. In orthopaedic and urologic surgery, specific endoscopic training usually takes place "on the job", e.g. at the operating room, on actual patients.

Those teachers replying to have structured courses for their residents were questioned if courses are obligatory (Fig. 8). According to $77 \%$ of respondents, this was the case. However, participation to the course is not in any way enforced by the majority (52.7\%) of teachers.

Considering having endoscopic skills training embedded in the (regional) endoscopic resident programme, a minority of teachers state to be aware of some form of evaluation of that particular training (41\%) (Fig. 9). No differences exist in evaluation trends between specialties (Chi-Square Kruskal-Wallis test: $6.733 ; P$-value $=0.081$ ).

Mean number of endoscopic training hours per resident per year was estimated to be 20.9 hours (Standard deviation 55.19 ); ranging from 0 hours ( $24.8 \%$ of respondents) to 460 hours ( $0.9 \%$ of respondents). Seventeen respondents had no clue how many hours this would be (question mark, 15\%), and $9.7 \%$, in fact, did not reply to this question.

With the assumption of specific endoscopic training tailored to the phase of training of the resident, teachers feel that residents not in training are not really eligible. Within the speciality training, most emphasis is put on the $6^{\text {th }}$ (last) year of formal residency training. Post-graduates should receive the most hours of specific, tailored endoscopic education (Table 1).

Effectiveness of training models for procedural endoscopic surgical skill

Overall, virtual reality (VR) procedural simulation was considered to be the most effective training modality in teaching procedural endoscopic surgical skill outside of the operating theatre (Fig. 10, mean 7.9, median 9.0). With a standard deviation of 2.0 only surpassed by the standard deviation of VR basic simulation (mean 7.7, median 8, standard deviation 1.98), respondents are uniform in their opinion.

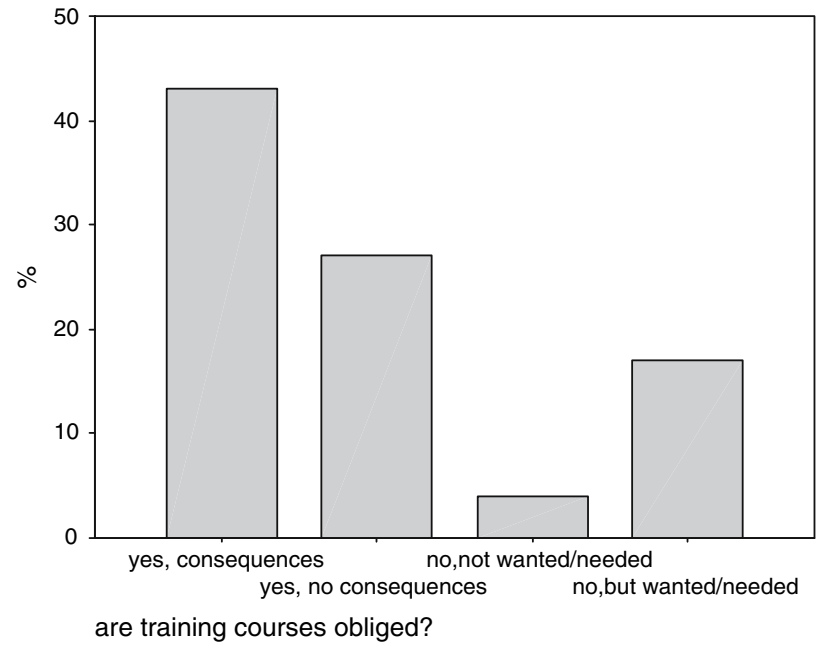

Fig. 8 Skill training obligatory 


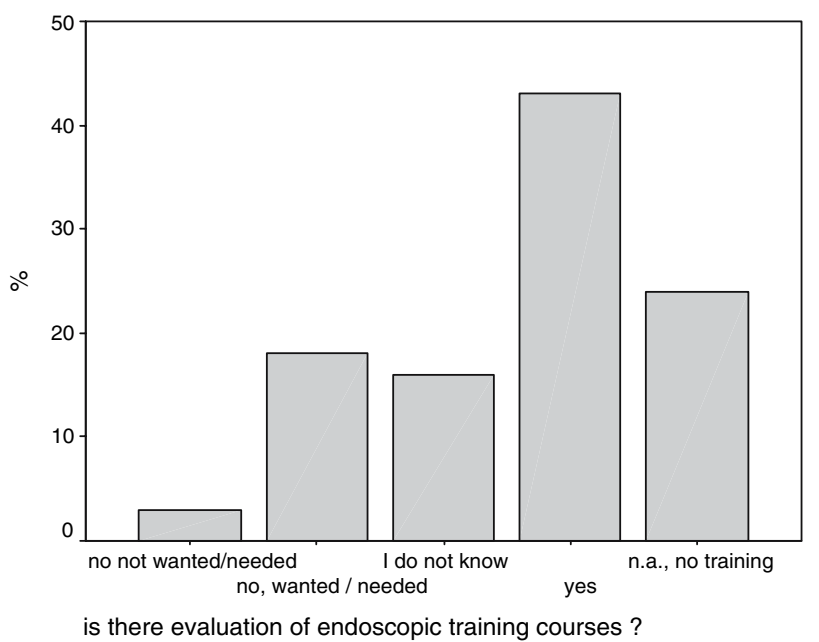

Fig. 9 Evaluation of endoscopic training

Fig. 10 and Table 2 display surgeons to believe strongly in VR procedural simulation. Human cadaver models for procedural training are considered least effective. In vivo animal model is regarded very effective for training as well, although much more controversy exists on the matter as displayed by the largest standard deviations (2.96).

In contrast, orthopaedic surgeons value human cadaver training models highly, and uniformly do so. VR basic and procedural simulation is considered "next best" in terms of effectiveness. Urologists value a variety of training modalities highly. Gynaecologists believe strongly in VR procedural simulation.

Endoscopic curriculum and skills laboratory

Most respondents (85.3\%) agreed that endoscopic skills training should be offered in a location especially equipped and suited for the purpose (the skills laboratory). No significant differences in opinion exist (Chi-Square KruskalWallis test: 6,$256 ; P$-value $=0.100$ ).

The "ideal" percentages of trainings modalities, needed to "build" effective and efficient endoscopic skills curricula, according to teachers, is displayed in figure 11 .

From figure 11, it is clear, that a combination of modalities is regarded to be most effective/efficient. It must

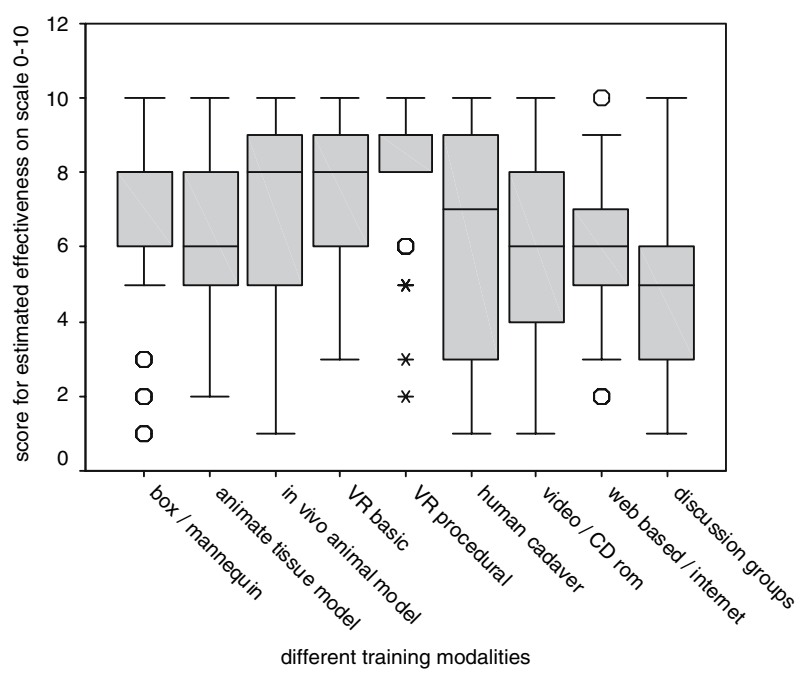

Fig. 10 Overall opinion of tutors on the effectiveness of different training modalities

be said, however, that not all program directors expressed their opinions on the matter so that percentages summed up to $100 \%$. Those respondents who did fully complete the percentage table $(n=52)$, feel that VR procedural simulation should be the cornerstone in building effective and efficient endoscopic training curricula (Table 3).

According to tutors, the endoscopic skills education should ideally be coordinated according to a national consensus/guidelines (Fig. 12). No differences exist in opinion among specialties (Chi-Square Kruskal-Wallis test: 1,254; Asymp. Sig 0,740). Most teachers believe that the practical execution of endoscopic skills training should be exerted within a central clinic, according to national guidelines, but (existing) regional regimens should be scrutinized for implementation considered appropriately and implemented in joint initiatives (Fig. 13).

All respondents but two orthopaedic surgeons agree $(98.1 \%)$ that education for endoscopic surgical skill should be an integral part of the specialist curriculum.

When endoscopic, validated skills training courses would exist, developed by and for the specific surgical profession, then teachers uniformly state that residents should "pass" such a training format before the resident may advance in training for the desired profession (Fig. 14; Pearson's Chi-square 2.52, Asymp. Sig. 2-sided 0.471).

Table 1 Number of hours of specific endoscopic training per resident per year ${ }^{\mathrm{a}}$

\begin{tabular}{lllllllll}
\hline & Resident not in training & $1^{\text {st }}$ year & $2^{\text {nd }}$ year & $3^{\text {rd }}$ year & $4^{\text {th }}$ year & $5^{\text {th }}$ year & $6^{\text {th }}$ year & Postgraduate (fellow) \\
\hline Mean & 4.95 & 14.15 & 17.27 & 16.93 & 16.96 & 14.38 & 19.92 & 25.50 \\
SD & 25.36 & 25.92 & 26.17 & 24.88 & 25.11 & 20.66 & 36.95 & 41.41 \\
\hline
\end{tabular}

SD, standard deviation

a Assumption: Training is designed specifically for the level of the resident 
Table 2 Opinion of tutors on effectiveness of training modalities

\begin{tabular}{lllllllllll}
\hline Speciality & & $\begin{array}{l}\text { Box } \\
\text { trainer/ } \\
\text { mannequin }\end{array}$ & $\begin{array}{l}\text { Animate } \\
\text { tissue } \\
\text { model }\end{array}$ & $\begin{array}{l}\text { In vivo } \\
\text { animal } \\
\text { model }\end{array}$ & $\begin{array}{l}\text { VR basic } \\
\text { endoscopy } \\
\text { simulation }\end{array}$ & $\begin{array}{l}\text { VR procedural } \\
\text { endoscopy } \\
\text { simulation }\end{array}$ & $\begin{array}{l}\text { Human } \\
\text { cadaver }\end{array}$ & $\begin{array}{l}\text { Video/ } \\
\text { CD ROM }\end{array}$ & $\begin{array}{l}\text { Web based/ } \\
\text { internet }\end{array}$ \\
\hline Surgery & Mean & 7.2963 & 6.5556 & 7.0357 & 7.2963 & 7.9583 & 5.3462 & 6.1923 & 5.5833 \\
& Median & 8.0000 & 7.0000 & 8.0000 & 8.0000 & 8.5000 & 5.0000 & 6.0000 & 6.0000 & 5.4800 \\
& SD & 2.4149 & 2.3912 & 2.9625 & 1.9771 & 2.0532 & 2.6524 & 2.6080 & 2.2442 \\
Orthopedic & 2.2935 \\
& Mean & 6.0000 & 4.0000 & 4.2500 & 6.8182 & 6.5833 & 8.3077 & 6.1333 & 6.0000 & 4.2500 \\
& Median & 6.0000 & 3.5000 & 3.0000 & 8.0000 & 6.5000 & 9.0000 & 6.0000 & 6.0000 & 4.0000 \\
Urology & SD & 2.3094 & 2.1381 & 3.2404 & 2.5620 & 2.6443 & 2.3939 & 2.6150 & 2.0000 & 2.0057 \\
& Mean & 7.4000 & 8.1429 & 8.7857 & 8.7857 & 8.4615 & 7.4286 & 6.4667 & 6.7500 & 4.9231 \\
Gynecology & Median & 8.0000 & 9.0000 & 9.5000 & 9.0000 & 9.0000 & 8.0000 & 7.0000 & 6.5000 & 5.0000 \\
& SD & 2.5014 & 1.7033 & 1.9287 & 1.3688 & 1.6132 & 2.6520 & 2.9729 & 2.8324 & 2.9570 \\
& Mean & 7.7308 & 6.7391 & 6.9524 & 8.0000 & 8.4500 & 5.6000 & 5.7692 & 5.2632 & 5.1304 \\
& Meduan & 8.0000 & 8.0000 & 8.0000 & 9.0000 & 9.0000 & 5.5000 & 6.0000 & 5.0000 & 5.0000 \\
\hline
\end{tabular}

VR, virtual reality; SD, standard deviation

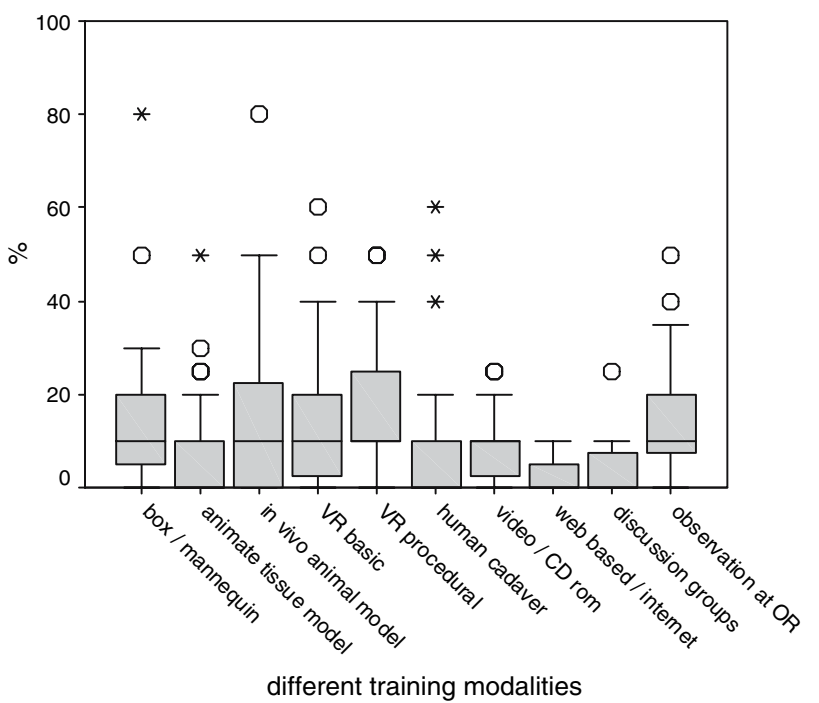

Fig. 11 Ideal percentages of training modalities embedded in endoscopic skills course

\section{Discussion}

From this questionnaire, it appears that over $90 \%$ of respondents perform endoscopic surgery, but only $55 \%$ of them claim to teach their residents in a structured format.
Thus, either 35\% does not teach at all, or teaches according to own initiative they themselves do not label as "skills training or course". Overall, specialists do not seem to differ much in opinion regarding training of endoscopic skills to residents, with the exception when asked for the actual situation regarding training residents' endoscopic skill. Surgeons (90\%) and gynaecologists (63.6\%) frequently report such initiatives. Only half $(50 \%)$ of urologists, and $33 \%$ of orthopaedic surgeons indicate to be aware of endoscopic resident training, and state initiatives to be present. What concerns authors, is the fact that almost $25 \%$ of surgical specialists responsible for resident training do not seem to have a clue how many hours of endoscopic training are, in fact, embedded within the training curriculum which they are responsible for.

Those program directors aware of initiatives, estimated the mean number of endoscopic training hours per resident per year to be 20.9 hours; e.g., $2 \frac{1}{2} 2$ day of training in endoscopic skills per year per resident. As a remark, surgeons indicate that the obligatory forms of training to be within the first two years of residency. In the Netherlands, orthopaedic and urologic residents are also 'covered' by these surgical training formats, as they complete the first two years of their specialist training within the general surgical department. Once being a third year resident, no

Table 3 Ideal combination for endoscopic skills training: percentage per tainings modality

\begin{tabular}{lllllllllll}
\hline & $\begin{array}{l}\text { Box } \\
\text { trainer/ } \\
\text { mannequin }\end{array}$ & $\begin{array}{l}\text { Animate } \\
\text { tissue } \\
\text { model }\end{array}$ & $\begin{array}{l}\text { In vivo } \\
\text { animal } \\
\text { model }\end{array}$ & $\begin{array}{l}\text { VR basic } \\
\text { endoscopic } \\
\text { simulation }\end{array}$ & $\begin{array}{l}\text { VR procedural } \\
\text { endoscopic } \\
\text { simulation }\end{array}$ & $\begin{array}{l}\text { Human } \\
\text { cadaver }\end{array}$ & $\begin{array}{l}\text { Video/ } \\
\text { CD ROM }\end{array}$ & $\begin{array}{l}\text { web based/ } \\
\text { internet }\end{array}$ & $\begin{array}{l}\text { discussion } \\
\text { groups }\end{array}$ & $\begin{array}{l}\text { Observation } \\
\text { at OR } \\
\text { Mean }\end{array}$ \\
14.58 & 6.44 & 13.66 & 15.61 & 16.57 & 8.73 & 8.71 & 3.93 & 4.11 \\
SD & 13.74 & 9.92 & 16.22 & 14.00 & 12.70 & 13.62 & 6.59 & 4.41 & 5.20 & 14.63 \\
\hline
\end{tabular}

VR, virtual reality; SD, standard deviation 


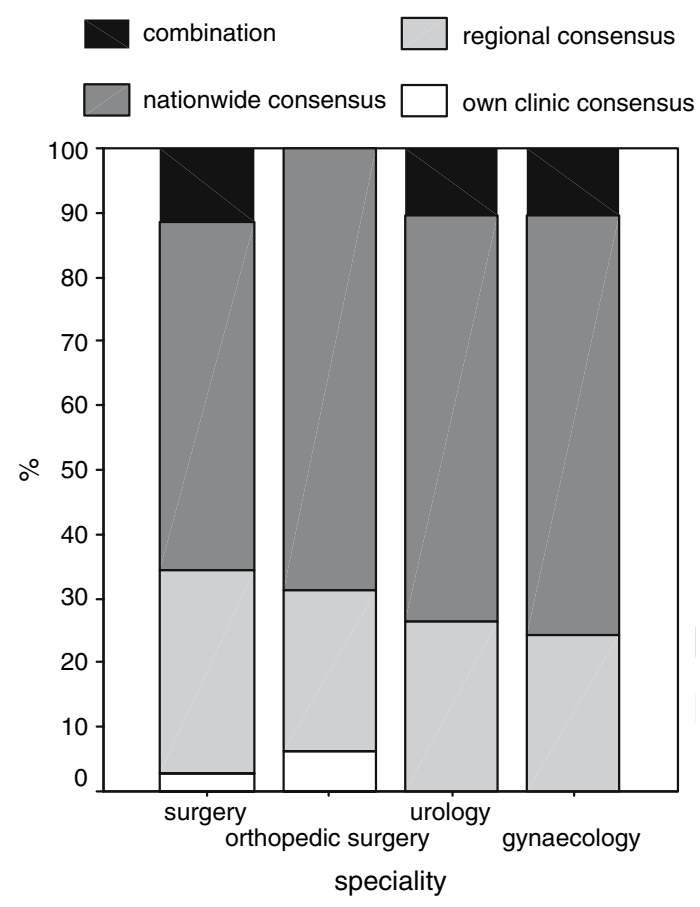

Fig. 12 Consensus guidelines

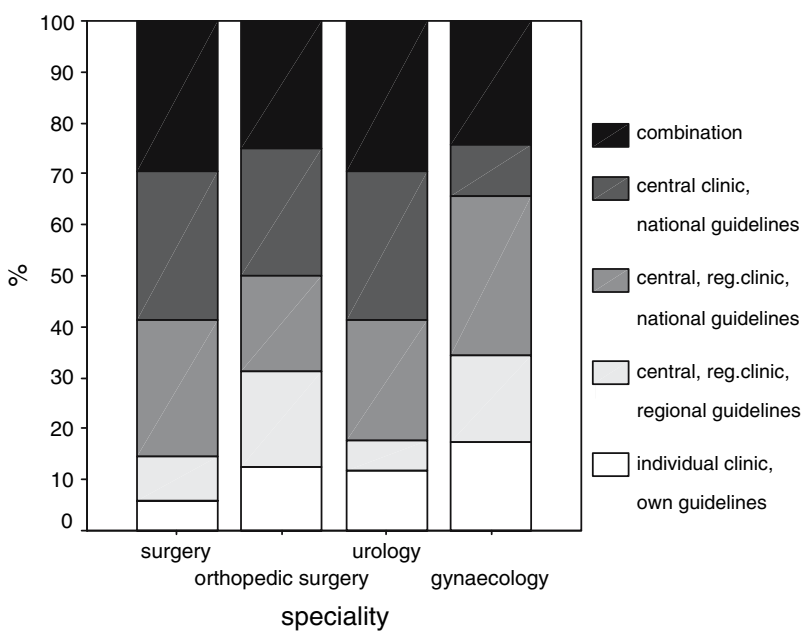

Fig. 13 Coordination and location for skills education

obligatory format of endoscopic training is indicated for surgeons and orthopaedic surgeons. As of 2006, urologists do have an obligatory national laparoscopy and endourology course embedded in the curriculum. Gynaecologists' training initiatives (COBRA-course for third year residents) were already mentioned.

Surgeons and orthopaedic program directors perceive the number of hours of obligatory endoscopic training to be sufficient. In contrast, the majority of urologists and gynaecologists assume this to be insufficient. Only the general surgical program directors are worried that the current working hour situation for residents might lead to an outcome problem, in terms of being adequately skilled

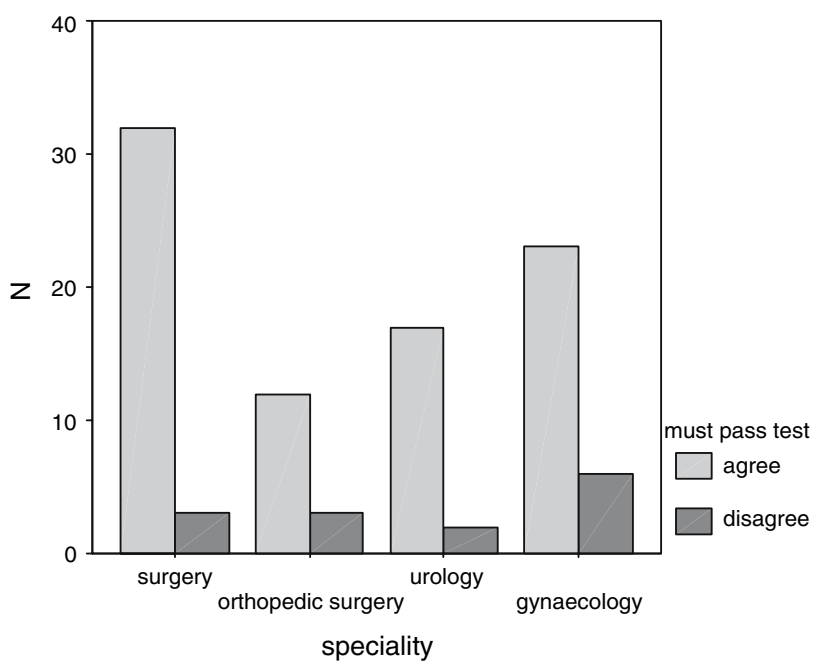

Fig. 14 Examination of course

for performance of endoscopic surgery upon completion of formal training. In the Netherlands, the surgical residents' perspective regarding endoscopic surgery has been investigated previously [18]. A majority of gastro-intestinal/ oncologic interested residents appeared to be very interested in performing advanced endoscopic surgery, but expect, in fact, to be incapable of doing so upon completion of training. Furthermore, one in every 10 general surgical residents expected to be inadequately trained for performing basic laparoscopic surgery (diagnostic laparoscopy, laparoscopic appendectomy and laparoscopic cholecystectomy) autonomous. This "outcome problem" may be perceived by general surgeons as well, being the only program directors group worrying substantially about endoscopic skills upon completion of training.

For gynaecologists, it is known that the percentage of hospitals having adopted polypectomy, myomectomy and endometrial ablation increased over $90 \%$ by the year 2002 in the Netherlandss [30]. It was concluded that implementation of basic, but not advanced hysteroscopic procedures, is successfully implemented in resident training by existing training initiatives and clinical practice [30]. Procedural skills training seems to be lacking for endoscopic gynaecologic surgery, and is indicated to be a problem. For training omissions in urologic and orthopaedic surgery, to date, no Dutch data exist.

Marked differences exist between the specialties regarding endoscopic training initiatives offered in their clinic or region. This can partly be explained by the fact that urologic and orthopaedic residents do have to fulfil 2 years of general surgical training. Within these 2 years, these residents follow the same program as their peers in training for general surgery, including the endoscopic training offered by the surgical training community. 
The method by which endoscopic surgical skill is taught, appears to be very heterogeneous in nature. In general surgery, no nation-wide format exists. Most often, some method of psychomotor skills training is offered (box training, Virtual Reality basic endoscopic skills training). Limited training hours are spent focussing on procedural endoscopic skill (laparoscopic appendectomy and/or laparoscopic cholecystectomy) within the curricula. The more advanced surgical procedures are not mentioned to be trained in any obligatory format the surgical curriculum. This is striking, as precisely the procedural endoscopic training is considered to be of great value among all program directors. This is reflected in a mean outcome score of 7.95 (ten-point scale) reflecting the effectiveness of training modalities for VR procedural training by specialists. Although trainers seem to be impressed by the potential of VR procedural training as can be deducted from figure 10, only a small minority indicates to train residents using VR. It is thus unclear if trainers can assess VR potential validly.

\section{Recommendations}

Consensus on the need for validated, national educational endoscopic training curricula and guidelines how to build and implement them, is mounting [17, 31-33]. Nevertheless, to date, worldwide only a few are known to exist [3438]. In order to generate optimal chances on implementation of such a national curriculum-to-be-developed, authors felt a primary investigation on issues regarding current and ideal endoscopic training from program directors to be mandatory. Program directors do subscribe the need for national guidelines on training endoscopic surgery highly, and uniformly.

Program directors feel that residents should be able to spend an increasing number of hours training procedural endoscopic surgery, as they progress in their specialist training. Over-all, the majority of specialists indicate $2 \frac{1}{2}$ day of endoscopic training per resident per year to be sufficient for delivering properly skilled surgeons upon completion of training. For urologists and gynaecologists, a majority indicates more training hours are to be recommended. A delicate balance between training hours and clinical working hours during residency exist. Due to working hours restrictions, residents cannot be permitted clinical absence for training each surgical procedure, as this will put too much of a burden on the clinic as well as on the resident. A competent surgical specialist is, after all, someone who is trained in patient contact on various levels, only one of them being proficient in practical endoscopic surgical skill. Authors suggest therefore that a re-allocation of available training hours, aimed at core-endoscopic basic and advanced procedures, tailored to the needs of the resident and phase of training, is in place.

A variety of procedural endoscopic training curricula need to be developed accordingly.

The professions need to define, which basic and advanced endoscopic procedures are to be trained, by whom, and by what outcome standards. It must be stated that not all residents will want, or need, to be trained in advanced procedures. But for those residents interested in advanced endoscopy, the current curriculum and clinical training situation is insufficient.

Within tailored curricula, a mixture of different training modalities, as can be deducted from Fig. 11, need to be embedded. Both respondents and authors feel that tailored, multi-dimensional training courses should ideally be taught within the combination of a regional and a central setting. According to the majority of program directors, virtual reality (VR) training needs to be cornerstone in developing procedural endoscopic training courses. Since surgeons learn at different rates, the importance of a repetitive training format cannot be overemphasized [39]. Realism is key, especially in training a procedural task, to surpass the individual learning curve efficiently [40]. VR simulation endorses above conditions.

Having outcome parameters structurally embedded in this type of high-end teaching technology, VR technology is able to support decisions in the competency area considerably. Besides, outcome results can quite effortlessly be implemented within the electronic portfolio, another instrument increasingly being implemented to monitor the resident within in the modern specialist training curriculum. As virtual reality simulation and procedural VR simulation in particular is costly equipment, much can be said for offering that part of the training course in a central location, e.g. a central skills laboratory. Training courses should be obligatory to the residents, with consequences for non-attendance. Evaluation of courses is, of course, mandatory.

In the near future, the resident surgeon will need to demonstrate competency, and he or she will be credited for it. An alternative setting, such as the skills laboratory, is the area where a new or infrequently performed procedure should be taught, and maybe not only to the resident [33]. For those residents interested in performing the high-end endoscopic procedures, specific endoscopic fellowships bridging the experience gap by one-on-one mentorship constructions are know to be highly effective and are therefore worth considering [41, 42]

National guidelines for procedural endoscopic surgery training programmes need to be developed and validated urgently. Next to defining which endoscopic procedures are to be taught, such guidelines must also focus on assessing competence, and therefore need to define outcome criteria. 
Residents must pass these criteria, before they are considered to be competent in starting clinical performance of the procedure. The Dutch Society of Endoscopic Surgery is believed to be the formal organization for taking up the task. Such programmes must be formally embedded within the residents training curriculum, respecting and integrating regional initiatives provided they have been properly evaluated, and shown to be successful. Only then, adoption within the surgical embodiments may be expected, beneficial to residents and ultimately, to patients.

\section{References}

1. Sauerland S, Agresta F, Bergamaschi R, Borzellino G, Budzynski A, Champault G, Fingerhut A, Isla A, Johansson M, Lundorff P, et al. (2006) Laparoscopy for abdominal emergencies: evidencebased guidelines of the European Association for Endoscopic Surgery. Surg Endosc 20(1):14-29

2. Neugebauer EA, Sauerland S (2006) Guidelines for emergency laparoscopy. World J Emerg Surg 19(1):31

3. Fingerhut A, Millat B, Bataille N, Yachouchi E, Dziri C, Boudet MJ, Paul A (2001) Laparoscopic hernia repair in 2000. Update of the European Association for Endoscopic Surgery (EAES). Surg Endosc 15(10):1061-1065

4. American society of colon, rectal surgeons (ASCRS) gastrointestinal and endoscopic surgeons (SAGES) Fleshman J, Marcello P, Stamos MJ, Wexner S (2006) Focus Group on Laparoscopic Colectomy Education as endorsed by the American Society of Colon and Rectal Surgeons (ASCRS) and the Society of American Gastrointestinal and Endoscopic Surgeons (SAGES): guidelines for laparoscopic colectomy course. Surg Endosc 20(7):1162-1167

5. no authors listed: (1999) Guidelines for diagnostic laparoscopy. SAGES guidelines. Society of American Gastrointestinal Endoscopic Surgeons. Surg Endosc 13(2):202-203

6. Ahmad G, Watson A, Vandekerckhove P, Lilford R (2006) Techniques for pelvic surgery in subfertility. Cochrane Database Syst Rev 19(2):CD000221

7. Tan BJ, Ost MC, Lee BR (2005) Laparoscopic nephroureterectomy with bladder-cuff resection: techniques and outcomes. J Endourol 19(6):664-676

8. European Association of Endoscopic Surgery (EAES), Veldkamp R, Gholghesaei M, Bonjer HJ, Meijer DW, Buunen M, Jeekel J, Anderberg B, Cuesta MA, Cuschieri A, Fingerhut A, et al. (2004) Laparoscopic resection of colon Cancer: consensus of the European Association of Endoscopic Surgery (EAES). Surg Endosc 18(8):1163-1185

9. Chronic Pelvic Pain/Endometriosis Working Group, Gambone JC, Mittman BS, Munro MG, Scialli AR, Winkel CA (2002) Consensus statement for the management of chronic pelvic pain and endometriosis: proceedings of an expert-panel consensus process. Fertil Steril 78(5):961-972

10. McCarthy JC, Lee J (2006) Hip arthroscopy: indications and technical pearls. Clin Orthop Relat Res 441:180-187

11. Murray H, Baakdah H, Bardell T, Tulandi T (2005) Diagnosis and treatment of ectopic pregnancy. CMAJ 173(8):905-912

12. Merlin TL, Scott DF, Rao MM, Wall DR, Francis DM, Bridgewater FH, Maddern GJ (2000) The safety and efficacy of laparoscopic live donor nephrectomy: a systematic review. Transplantation 70(12):1659-1666

13. Neugebauer E, Troidl H, Kum CK, Eypasch E, Miserez M, Paul A (1995) The E.A.E.S. Consensus Development Conferences on laparoscopic cholecystectomy, appendectomy, and hernia repair. Consensus statements-September 1994. The Educational Committee of the European Association for Endoscopic Surgery. Surg Endosc 9(5):550-563

14. Figert PL, Park AE, Witzke DB, Schwartz RW (2001) Transfer of training in acquiring laparoscopic skills. J Am Coll Surg 193(5):533-537

15. Bevan PG (1986) Craft workshops in surgery. Br J Surg 73:1-2

16. Liberman MA, Greason K (1999) Residency training in advanced laparoscopic surgery: how are we doing? Surg Laparosc Endosc Percutan Tech 9(2):87-90

17. Park A, Witzke DB (2002) Training and educational approaches to minimally invasive surgery: state of the art. Semin Laparosc Surg 9(4):198-205

18. Schijven MP, Berlage JTM, Jakimowicz J (2004) Minimal access surgery training in the Netherlands. A survey among residents-intraining for general surgery. Surg Endosc 18:1805-1814

19. Chiasson PM, Pace DE, Schlachta CM, Mamazza J, Poulin EC (2003) Minimally invasive surgery training in Canada. A survey of general surgery. Surg Endosc 17:371-377

20. Chung R, Pham Q, Wojtasik L, Chari V, Chen P (2003) The laparoscopic experience of surgical graduates in the United States. Surg Endosc 17:1792-1795

21. Grantcharov TP: Teaching and testing surgical skills on a VR laparoscopy simulator- learning curves and effect of previous operative experience on performance. In: 10th International congress of the European Association for Endoscopic Surgery: 2002; Lisboa, Portugal; 2002: 23 abstract nr. 0065

22. Schijven M, Jakimowicz J (2003) Construct validity: experts and residents performing on the Xitact LS500 laparoscopy simulator. Surg Endosc 17:803-810

23. Grantcharov TP, Bardram L, Funch-Jensen P, Rosenberg J (2003) Learning curves and impact of previous operative experience on performing on a virtual reality simulator to test laparoscopic surgical skills. Am J Surg 185(2):146-149

24. Schijven MP, Jackimowicz JJ (2003) The learning curve on the Xitact LS500® laparoscopy simulator: profiles of performance. Surg Endosc 18:121-127

25. Di Giulio E, Fregonese D, Casetti T (2004) Training with a computer based simulator achieves basic manual skills required for upper endoscopy: a randomized controlled trial. Gastrointest Endosc 60:196-200

26. Grantcharov TP, Kristiansen VB, Bendix J, Bardram L, Rosenberg J, Funch-Jensen P (2004) Randomized clinical trail of virtual reality simulation for laparoscopic skills training. $\mathrm{Br} \mathrm{J}$ Surg 91:146-150

27. Chou DS, Abdelshehid C, Clayman RV, McDougall EM (2006) Comparison of results of virtual-reality simulator and training model for basic ureteroscopy training. J Endourol 20(4):266-271

28. Knudsen BE, Matsumoto ED, Chew BH, Johnson B, Margulis V, Cadeddu JA, Pearle MS, Pautler SE, Denstedt JD (2006) A randomized, controlled, prospective study validating the acquisition of percutaneous renal collecting system access skills using a computer based hybrid virtual reality surgical simulator: phase I J Urol 176(5):2173-2178

29. Cohen J, Cohen SA, Vora KC, Xue X, Burdick JS, Bank S, Bini EJ, Bodenheimer H, Cerulli M, Gerdes H, et al. (2006) Multicenter, randomized, controlled trial of virtual-reality simulator training in acquisition of competency in colonoscopy. Gastrointest Endosc 64(3):361-368

30. van Dongen H, Kolkman W, Jansen FW (2006) Hysteroscopic surgery: Perspectives on skills training. J Minim Invasive Gynecol 13(2):121-125

31. Cushieri A (1993) Reflections on surgical training. Surg Endosc 7:73-74 
32. Work Group for Evaluation and Implementation of Simulators and Skills Training Programmes Carter FJ, Schijven MP, Aggarwal R, Grantcharov T, Francis NK, Hanna GB, Jakimowicz JJ (2005) Consensus guidelines for validation of virtual reality surgical simulators. Surg Endosc 19(12):1523-1532

33. MacFadyen Jr, BV (2004) Teaching, training, and clinical surgery. Surg Endosc 18:361-362

34. Royston CM, Lansdown MR, Brough WA (1994) Teaching laparoscopic surgery: the need for guidelines. BMJ 308(6935):1023-1025

35. Matsuda T, Ono Y, Terachi T, Naito S, Baba S, Miki T, Hirao Y, Okuyama A (2006) The endoscopic surgical skill qualification system in urological laparoscopy: a novel system in Japan. J Urol 176(5):2168-2172

36. Swanstrom LL, Park A, Arregui M, Franklin M, Smith CD, Blaney C (2006) Bringing order to the chaos: developing a matching process for minimally invasive and gastrointestinal postgraduate fellowships. Ann Surg 243(4):431-435

37. Jamieson J (1997) Guidelines on training and credentialling for the practice of minimal access surgery (MAS). Recommendations of the South African Society of Endoscopic Surgeons (SASES). S Afr J Surg 35(1):8-9
38. Society of American Gastrointestinal Endoscopic Surgeons SAGES: Framework for post-residency surgical education \& training. A SAGES guideline. wwwsagesorg/sagespublicationprintpho?doc $=17,2003$

39. Stefanidis D, Korndorffer Jr JR, Markley S, Sierra R, Scott DJ (2006) Proficiency maintenance: impact of ongoing simulator training on laparoscopic skill retention. J Am Coll Surg 202(4):559-603

40. Schijven MP, Jakimowicz JJ, Broeders IAMJ, Tseng LNL (2005) The Eindhoven laparoscopic cholecystectomy training course: improving operating room performance using Virtual Reality Training. Results from the first E.A.E.S. accredited virtual reality trainings curriculum. Surg Endosc 19:1220-1226

41. Myers JA, Doolas A (2006) How to teach an old dog new tricks and how to teach a new dog old tricks: bridging the generation gap to pusch the envelope of advanced laparoscopy. Surg Endosc 20:1117-1178

42. Thuraisingam AI, MacDonald J, Shaw IS (2006) Insights into endoscopy training: a qualitative study of learning experience. Medical Teacher 28(5):453-459 